\title{
Effect of Educational Program on Knowledge and Health Care Practices about Nephrotic Syndrome among Mothers of Pre-School Children
}

\author{
Nagat F. Abolwafa ${ }^{1}$, Yosria El-Sayed Hossein ${ }^{2, *}$ \\ ${ }^{1}$ Pediatric Nursing Department, Faculty of Nursing, Minia University \\ ${ }^{2}$ Community Health Nursing Department, Faculty of Nursing, Minia University \\ *Corresponding author: yosria1968@yahoo.com
}

\begin{abstract}
Background: Nephrotic syndrome is a clinical state that is common in preschool children includes massive proteinuria, hypoalbuminemia, hyperlipemia, and edema. Mothers are the primary care giver; if they have adequate knowledge and awareness about therapeutic facilities to treat children from nephrotic syndrome through educational program. The aim of the study: to evaluate the effect of educational program on knowledge and health care practices about nephrotic syndrome among mothers of pre-school children. Design: pretest-posttest design was utilized to conduct this study. Setting: The study conducted in pediatric word at Minia University Hospital for Obstetrics and Pediatrics Sample: 50 mothers of pre-school children about nephrotic syndrome. Tools: Pre-designed questionnaire sheet, sheet about reported practices and Educational program. Results: Result of this study showed significant improvement in mothers knowledge and health care practices about nephrotic syndrome in post/test. Conclusion: After program implementation there was remarkable improvement of mothers knowledge and health care practices about nephrotic syndrome. Recommendations: A developed program should be applied and repeat again in the same study setting.
\end{abstract}

Keywords: Health Care Practices Knowledge, Mothers of Pre-School Children, Nephrotic Syndrome

Cite This Article: Nagat F. Abolwafa, and Yosria El-Sayed Hossein, "Effect of Educational Program on Knowledge and Health Care Practices about Nephrotic Syndrome among Mothers of Pre-School Children." American Journal of Nursing Research, vol. 6, no. 5 (2018): 244-252. doi: 10.12691/ajnr-6-5-5.

\section{Introduction}

Children's are tomorrow's citizens, a well-developed child adds to the nation welfare and children are the precious resources of the nation. The most precious resources of any country are children. It is our responsibility to protect them against all forms of exploitation and discrimination. Each new child offers humanity another chance for survival, a child is considered as the future hope of the family and as an individual he will determine the kind of status the family would gain in the future [1].

Healthy children become healthy adults, people who create better lives for themselves, their communities and their countries. Improving the health of children is one responsibility among many in the fight against poverty. The Children of today are the resources of the future. Preservation of their lives will always be a priority. Child health includes the care of the children from infancy to adolescence [2].

Nephrotic Syndrome is a group of signs and symptoms including low blood protein, proteinuria and hyperlipidemia. The most common symptoms of idiopathic nephrotic syndrome include edema, generalized edema. Nephrotic syndrome is a primarily pediatric disorder which initially noted around the eyes and in the lower extremities and with the time the edema becomes generalized [3] and [4].

Edema is the presenting symptom in about $95 \%$ of children with NS. Early on, the edema is intermittent and insidious noted mostly in the periorbital, scrotal, and labial regions, symptoms of infection can be diagnosed, such as fever, lethargy, irritability, or abdominal pain weight gain and ascites while hypertension and gross hematuria are uncommon [5].

Primary (Idiopathic) nephrotic syndrome is the most common type about $(90 \%)$ of children who present with the typical features of nephrotic syndrome [6]. The exact cause of nephrotic syndrome is unknown and it cannot be prevented, however many diseases and conditions can cause glomerular damage and lead to nephrotic syndrome. It may be primary (idiopathic) NS $(90 \%)$ as MCNS, membranous nephropathy or congenital nephrotic syndrome as congenital syphilis or secondary nephrotic syndrome as use of certain drugs or certain immune diseases, after infections as hepatitis B and C, Human Immune Deficiency Virus (HIV) [7] and [8].

Nephrotic syndrome is a disease that can be seen all over the world the annual incidence rate of nephrotic syndrome in children aged below 16 years is 2 to 7 new cases per 100000 , with a prevalence rate of 16 cases per 100 000. Incidence peaks between 2-5 years old. Male are 
more affected than female the ratio is 2:1 [9] and [10]. Nephrotic Syndrome is 15 times more common in children than adults and affects 16 in 100,000 children worldwide/year, making this with the development of ascites, pleural effusion, condition one of the common childhood kidney diseases genital edema, weight gain, oliguria, anorexia, irritability and the ratio of males to females is approximately $2: 1$ [1].

The incidence of idiopathic Nephrotic syndrome in the United States has been reported to be 2.7 new cases per 100,000 children per year, and the cumulative prevalence rate is 16 per 100,000 children. The ratio of males to females is approximately $2: 1$ during childhood. There is an increased familial incidence, particularly among siblings. The infection of the genitourinary system commonly seen in children is Nephrotic syndrome [6].

The main aim of therapeutic management is reducing excretion of protein in urine, reducing retention of fluids in tissues preventing infection and minimizes complication related to therapies [11]. Treatment for nephrotic syndrome includes initial treatment as starting treatment with prednisolone and nonspecific treatment as antihypertensive therapy. Immunosuppressive drugs, antibiotic prophylaxis, and supportive treatment as include diet, high in protein and fiber but low in saturated fat and salts children with mild to moderate edema may be managed in out-patients clinics [12] and [13].

Nurses should assess child's condition but the first priority is to assess the child's fluid status as the hypoalbuminemia predisposes the child to the risk of developing hypovolemia. Whereas nursing interventions involves administering medications which are diuretics, antibiotics and corticosteroids as prescribed. Asking dietitian to plan a low sodium diet with moderate amount of protein, instructing children in restricting fluid intake, providing meticulous skin care to combat edema, encouraging activity and exercise, monitoring and document the location and character of edema, monitoring intake and output hourly and stressing the importance of adhering to the special diet [9].

Hospitalization causes certain changes in routine, such as change in family dynamics, the disruption or delay in education, the effective deficiencies, maternal deprivation, physical and psychological aggression, so that the child, who is ill and hospitalized, becomes more fragile and sensitive emotionally. In this sense, the impact of nephritic syndrome can be reflected in several areas of the child's life, possibly interfering on the chances for a healthy socio-emotional development and sharing in children activities, limiting the independence of the child, since parents usually control the habits of children and contact with other children, in order to protect them, for fear that the child can get infections. This limitation affects the understanding and acceptance of the disease by the child [14] and [15].

\subsection{Significant of the study}

Nephrotic syndrome among Egyptian children there was 243 deaths annually are due to nephrotic syndrome, this ranks Egypt as the second country in the world in this regard, preceded only by Japan which tallies up to 447 deaths, the united states follow closely behind Egypt with 153 deaths [16] and [17].

So having knowledge and health related practice regarding chronic illness such as nephrotic syndrome improve child and family health outcomes by promoting recovery, prevent relapse, promoting health behavior. Important of education program for helping mothers and the child to cope by providing information and helping mothers to understand what choices they have. Therefore developing and applying educational program for mothers of pre-school children about nephrotic syndrome, are very important and beneficial in terms of quality of care to decrease morbidity and mortality in addition to lessen the burden on families, hospitals and the community as well.

\subsection{The aim of the study}

The aim of this study to evaluate the effect of educational program on knowledge and health care practices about nephrotic syndrome among mothers of pre-school children

\subsection{Research design}

Pretest-posttest research design was utilized to meet the aim of this study.

\section{Subjects and Methods}

\subsection{Sampling and population}

This study was conducted in pediatric word at Minia University Hospital for Obstetrics and pediatrics. Fifty (50) mothers of pre- school children have nephrotic syndrome at Minia University Hospital for Obstetrics and Pediatrics. Inclusion criteria; Mothers of pre-school children have nephrotic syndrome admitted to pediatric word at Minia University Hospital for Obstetrics and Pediatrics; Mothers who are willing to participate in the study. Exclusion criteria; Mothers of children with congenital anomalies or mental illness. As well mothers refuse to participate in the study.

\subsection{Tools for data collection}

Two tools were used in this study and developed by the researcher, based on related literatures, to collect the necessary data for this study, which divided as the followings:

\section{Tool I:}

Pre-designed questionnaire sheet for mothers as pre/post that was designed by the researcher after reviewing of the related literature to assess the mothers pre-school children knowledge about nephrotic syndrome.

\section{It included the following parts}

1. Personal data: as children age, sex, mothers age, qualification, number of children, residence, family income 
2. Mothers knowledge about nephrotic syndrome (definition of disease, causes, signs and symptoms, investigations done to the child, nephrotic syndrome specific diet, early signs of infection, oral medication and side effects.

Tool II: Health care practice sheet: questions for each mothers which cover their reported practice regarding management of nephrotic syndrome such as general hygiene practices, regular follow-up measures such as (measuring weight, intake and output, measuring temperature, blood pressure and check protein in urine), administration of medication, proper following of nutrition and psychological reassurance of the child.

\section{Scoring System}

Scoring system for data collection from knowledge and reported health care practices questionnaire sheet Scoring system was graded according to the items of the interviewing questionnaire sheet; mother answers were evaluated using model answer sheet prepared by the researcher. A score of one was given for correct answer and a zero for incorrect answer. For each part, the scores of the items were summed up and the total divided by number of the items, giving a mean score for the part. These scores were converted into a percent score and mean and standard deviations were computed. The total mothers knowledge and reported health practices were scored as less than $50 \%$ was considered as unsatisfactory while score of $50 \%$ and more is considered as satisfactory.

\subsection{Validity and Reliability}

The tool was tested the content validity by a jury of three experts in the field of the study to test the content validity of tool and necessary modifications were done. Reliability of the tool was performed to confirm its consistency using Cronbach's alpha coefficient method.

\subsection{Pilot Study}

A pilot study on $(10 \%) 5$ mothers was conducted at Minia University Hospital for Obstetrics and Pediatrics. A pilot study was conducted to test clarity \& completeness of the study tools and to determine the time required to fill each tool. According to the results of pilot, the needed modification, omissions and/or additions were done. A jury acceptance of the final forms was secured before actual study work and the reliability was assessed in a pilot study by measuring their internal consistency using Cronbach's alpha coefficient method.

\subsection{Ethical Consideration}

The oral consent was obtained from all mothers to participate in the study and the nature and purpose of the study were explained to them. The researchers initially introduced themselves to all optional subjects and they were assured that the collected data would be absolutely confidential. They were informed that participation is voluntary and that they could withdraw at any time of the study. Confidentiality of the mothers data was ascertained. Confidentiality and anonymity were assured.

\subsection{Educational Program}

The researchers prepared educational booklet after assessment of knowledge to identify of needs of mothers pre-school children about nephrotic syndrome in a form of printed (Arabic booklet). Information based on review of relevant literature (nursing textbook, journal and internet resources) about nephrotic syndrome.

\section{Field work}

The field work was carried out through a period of 6 months starting from September 2017 to February 2018; the time required for the program implementation was 6 months. One month for pre/post-test, 5 months for implementation of the program. Mothers of pre-school children was divided into 10 small groups each group has 5 mothers. There was total 6 sessions for each group; each session was variable and ranged between 45-60 minutes. Each participant gets a copy of the program booklet that included all the educational materials. Each session usually started by a summary of what has been taught during the preceding sessions and the objectives of the new one. Giving praise and/or recognition to the interested mothers were used for motivation during program implementation.

The actual work started as preparatory or assessment phase, by meeting the mothers in pediatric ward at Minia University Hospital for Obstetrics and Pediatrics., the researcher first introduced herself to them and gave them a complete back ground about the study, it's aim, then the pre-test format, was distributed in order to collect the required data. The researcher was available for more clarification whenever needed. Then, the planning phase was designed based on content of the program, actual educational need assessment of the studied mothers. Consequently, the subject content has been sequenced through theoretical sessions. Implementation phase conducted through, The session 1, content: personal interviewing of the studied mothers, the aim, duration of the study explained by the researcher through direct personal communication, mother class and discussion and pre-test. The session 2, content: definition of nephrotic syndrome, causes, signs and symptoms, investigations done to the child. The session 3, content: nephrotic syndrome specific diet, early signs of infection, oral medication and side effects. The session 4, content: Health related practice regarding management of nephrotic syndrome such as general hygiene practices, regular follow-up measures such as: measuring weight, intake and output, measuring temperature. The session 5, content: blood pressure and check protein in urine, administration of medication, proper following of nutrition and psychological reassurance of the child. The session 6, content: Revision. Methods of teaching were through mother class and group discussion. At the last, evaluation phase, post-test format was distributed in order to collect the required data.

\section{Data Analysis}

Data entry was done using compatible personal computer. The statistically analysis was done using 
SPSS-20 statistical software package. The content of each tool was analyzed, categorized and then coded. Data were presented using descriptive statistics in the form of frequencies and percentages for qualitative variables, and means and standard deviations for quantitative variables. Quantitative continuous data were compared by using student T-test in case of comparisons between the mean scores of the two studied groups. Qualitative studied variables were compared using Chi-square test. Statistical significance was used at $\mathrm{P}$. value $<0.05$

\section{Results}

Table 1 shows that, $38 \%$ of mothers age from $30: 39$ years, with mean age $36.3 \pm .9 .2$. Their formal education revealed that, $30 \%$ of mothers have secondary school. Regarding residence, $64 \%$ of mothers live in rural but $36 \%$ were living in urban. In addition $40 \%$ of mothers have more than 6 children. Regarding monthly income; $80 \%$ of mothers get in-adequate income.

Table $2 \&$ Figure 1 illustrates that $16 \%$ of mothers knowledge about meaning of nephrotic syndrome in pre-test but $92 \%$ of mothers of children of pre-school children in post-test. Regarding signs and symptoms of nephrotic syndrome, $22 \%$ say the signs and symptoms of nephrotic syndrome in pre-test but $86 \%$ say the signs and symptoms of nephrotic syndrome in post-test. $16 \%$ of mothers know specific diet of nephrotic syndrome in pre- test and $92 \%$ in post-test. $10 \%$ of mothers know oral medication and side effects of nephrotic syndrome in pre-test and $96 \%$ in post-test. However, this increase reached statistically significant difference between the mothers of children pre-school children know definition, signs and symptoms, specific diet and oral medication and side effects of nephrotic syndrome (P. 0.02, 0.03,0.03 and 0.04); respectively.

Table 1. Distribution of mothers characteristics about nephrotic syndrome $(n=50)$

\begin{tabular}{|c|c|c|}
\hline Items & No & $\%$ \\
\hline 1. Age in years of mothers: & & \\
\hline - Under 20: 29 years & 15 & 30 \\
\hline $\begin{array}{l}\text { - From } 30: 39 \text { years } \\
\text { - } 40 \text { and more }\end{array}$ & $\begin{array}{l}19 \\
16\end{array}$ & $\begin{array}{l}38 \\
32\end{array}$ \\
\hline Mean $\pm \mathrm{SD}$ & \multicolumn{2}{|c|}{$36.3 \pm 9.2$} \\
\hline 2. Sex of pre-school children: & & \\
\hline - Mal & 30 & 60 \\
\hline - Female & 20 & 40 \\
\hline \multicolumn{3}{|l|}{ 3. Formal education } \\
\hline - Cannot read and write & 14 & 28 \\
\hline - Primary School & 11 & 22 \\
\hline - Secondary School & 15 & 30 \\
\hline - Higher Education & 10 & 20 \\
\hline \multicolumn{3}{|l|}{ 4. Residence: } \\
\hline - Rural & 32 & 64 \\
\hline - Urban & 18 & 36 \\
\hline \multicolumn{3}{|l|}{ 5. Number of children : } \\
\hline - From 1-3children & 13 & 26 \\
\hline - From 4-6 children & 17 & 34 \\
\hline - More than 6 children & 20 & 40 \\
\hline \multicolumn{3}{|l|}{ Monthly income } \\
\hline - Adequate & 10 & 20 \\
\hline - In-adequate & 40 & 80 \\
\hline
\end{tabular}

Table 2. Distribution of mothers of pre- school children according to their knowledge about nephrotic syndrome $\mathbf{n}=\mathbf{5 0}$

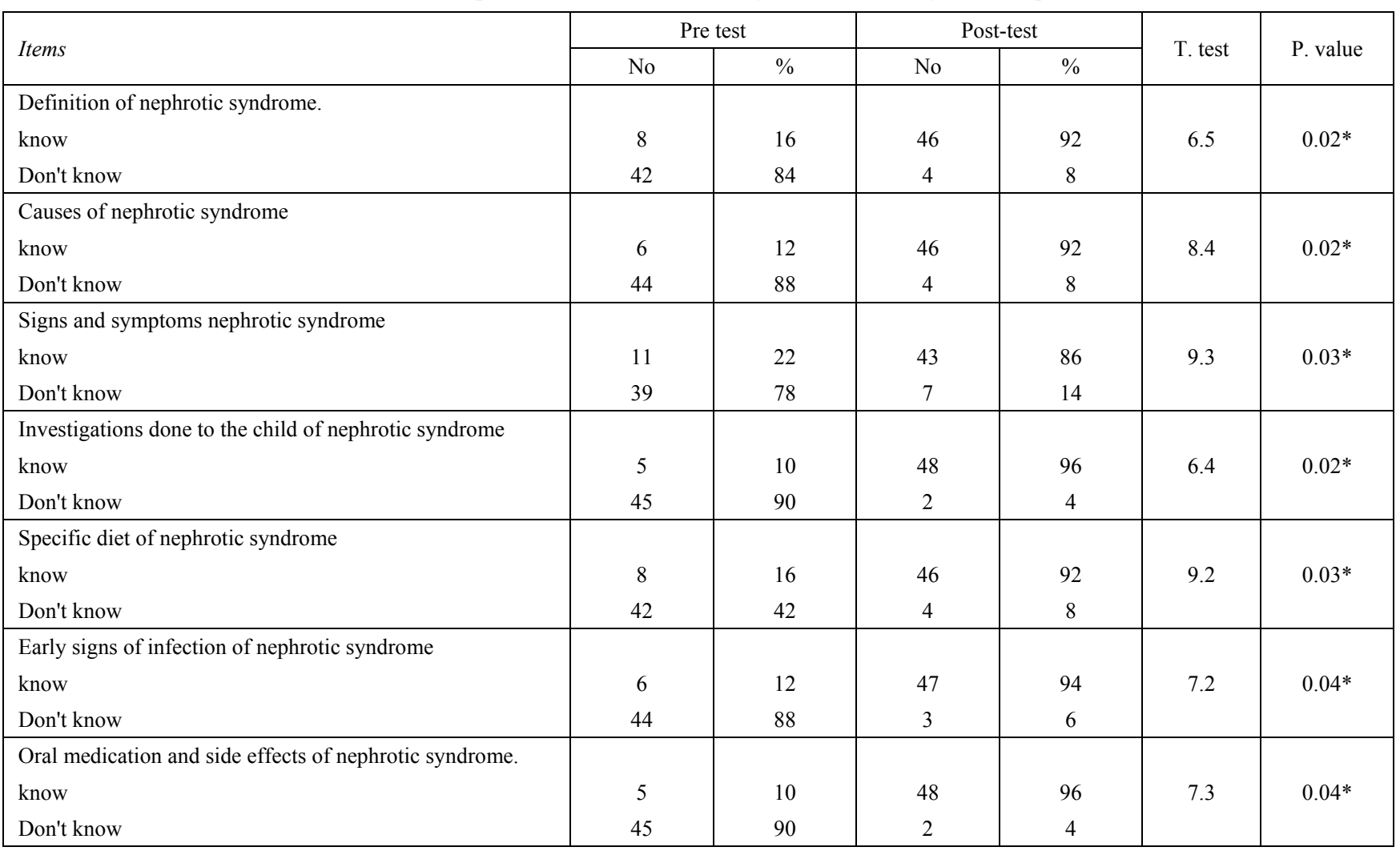




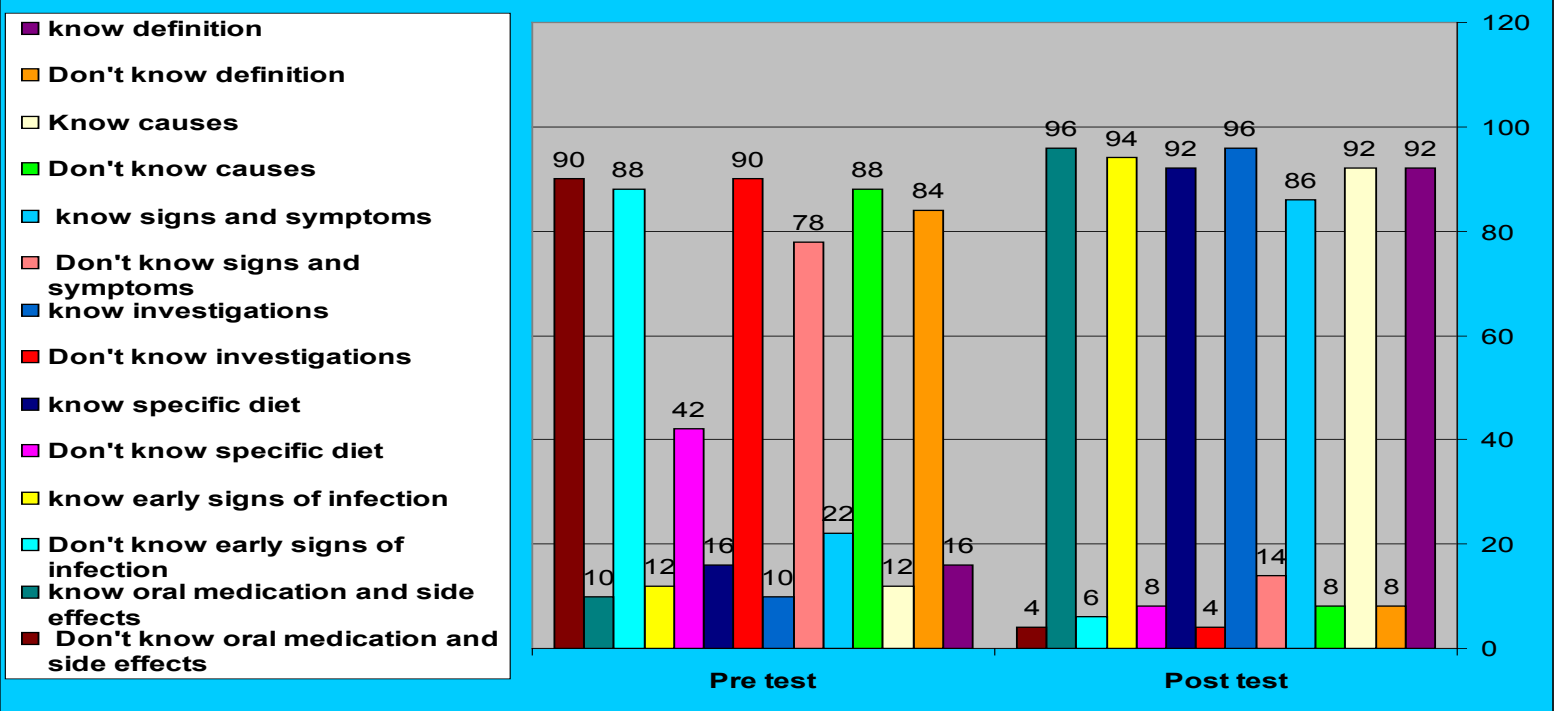

Figure 1. Distribution of mothers of pre- school children according to their knowledge about nephrotic syndrome

Table 3. The relation between the studied sample knowledge about nephrotic syndrome and their characteristics $\mathbf{n}=50$

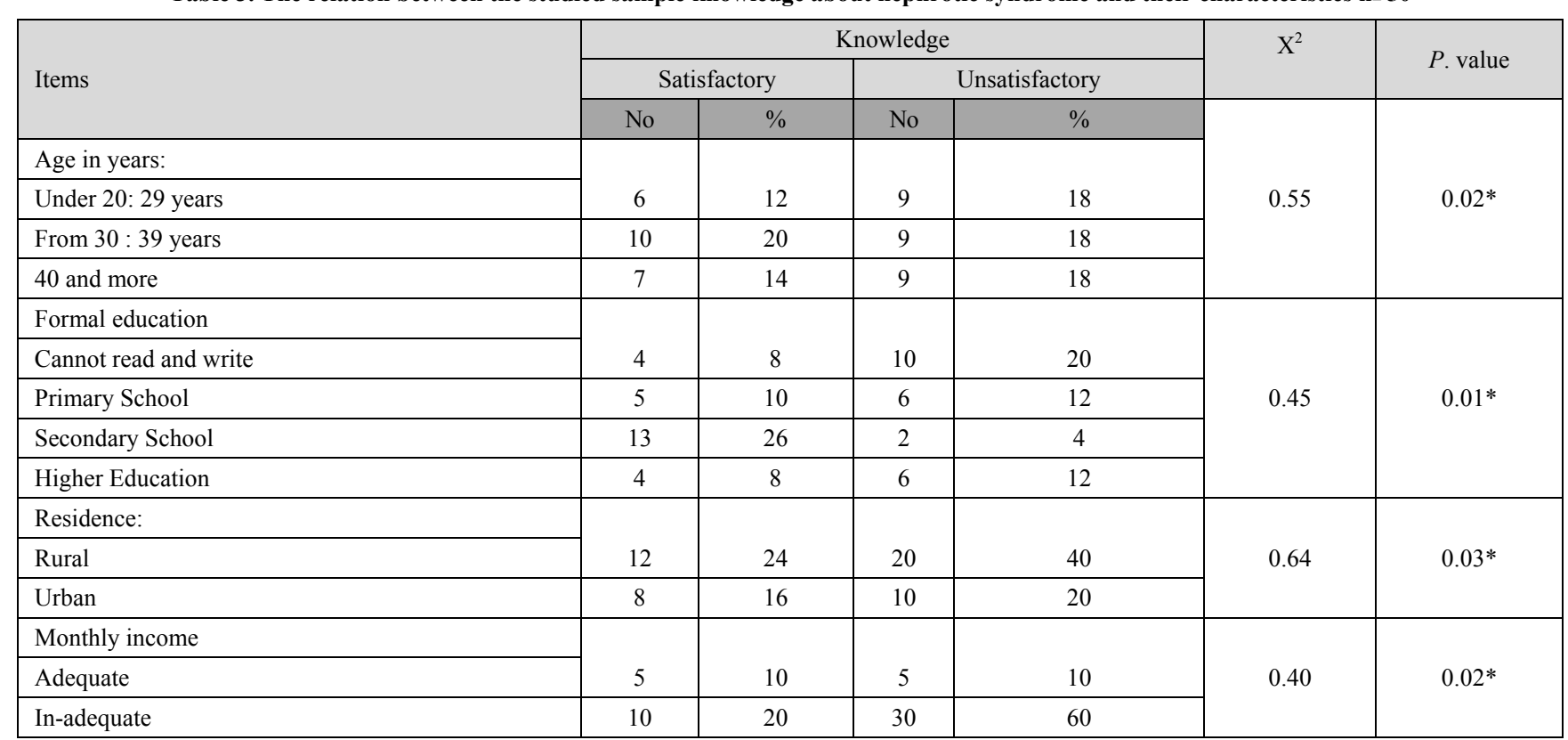

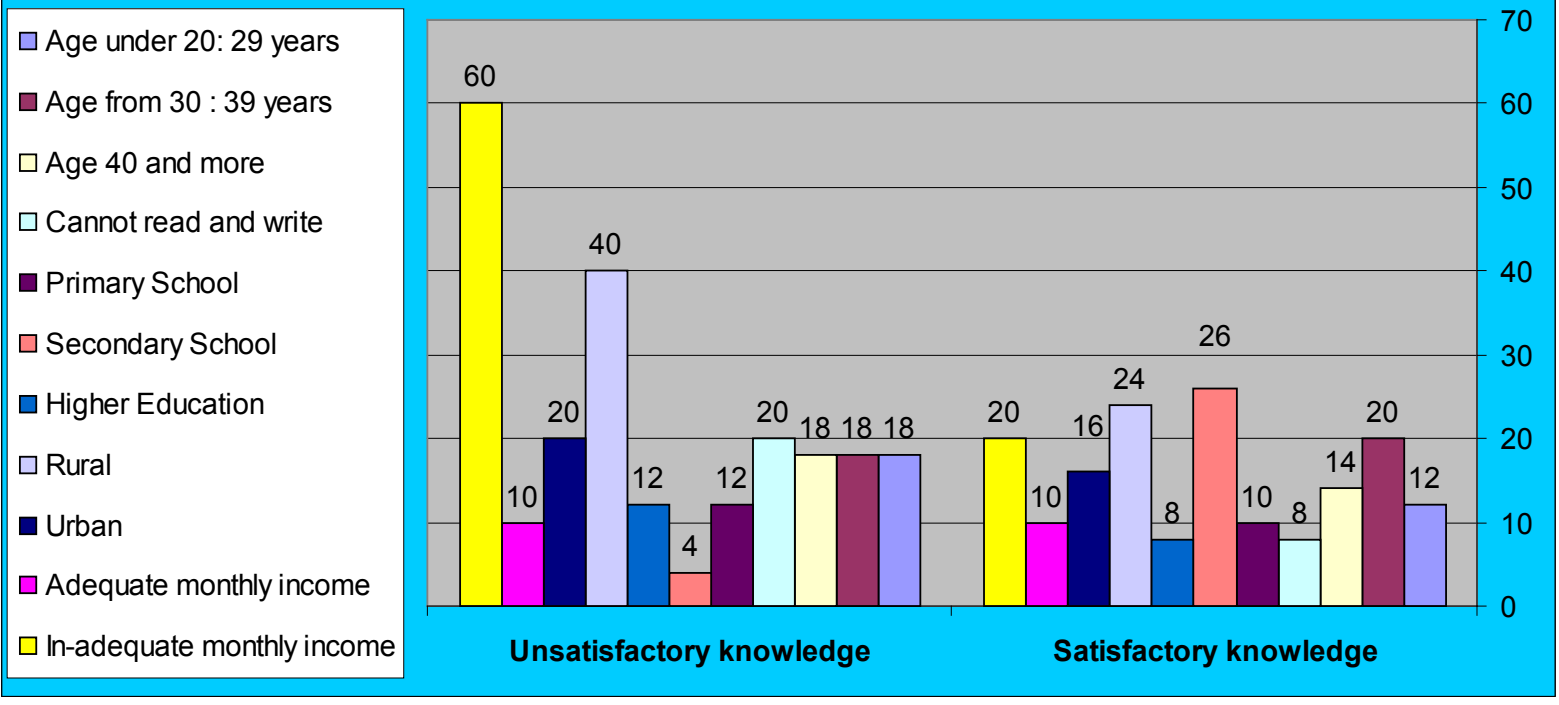

Figure 2. The relation between the studied sample knowledge about nephrotic syndrome and their characteristics 
Table $3 \&$ Figure 2 this table revealed that, the relation between the studied sample knowledge about nephrotic syndrome in pre-school children and their characteristics. It indicates an increase in satisfactory knowledge of mothers age from $30: 39$ years were $20 \%, 26 \%$ of mothers have secondary school education, $24 \%$ of mothers in rural and $20 \%$ of mothers have in-adequate income. However, this increase reached statistically significant difference between the mothers age, formal education, residence and monthly income and their knowledge (P. 0.02, 0.01, 0.03 and 0.02 ); respectively.
Table 4 \& Figure 3 reveals that $22 \%$ of mothers have satisfactory reported general hygiene practices in pre-test and $88 \%$ in post-test, $18 \%$ of mothers have satisfactory reported regular follow-up measures in pre-test and $88 \%$ in post-test, $18 \%$ of mothers have satisfactory reported administration of medication in pre-test and $90 \%$ in post-test, $20 \%$ of mothers have satisfactory reported proper following of nutrition in pre-test and $92 \%$ in post-test, $10 \%$ of mothers have satisfactory reported psychological reassurance of the child. in pre-test and $94 \%$ in post-test. However, this increase reached statistically significant difference.

Table 4. Distribution of mothers of pre-school children according to their reported health care practices $n=50$

\begin{tabular}{|c|c|c|c|c|c|c|c|c|c|}
\hline \multirow{3}{*}{ Items } & \multicolumn{4}{|c|}{ Pre-test } & \multicolumn{4}{|c|}{ Post-test } & \multirow{3}{*}{ P. value } \\
\hline & \multicolumn{2}{|c|}{ Satisfactory } & \multicolumn{2}{|c|}{ Unsatisfactory } & \multicolumn{2}{|c|}{ Satisfactory } & \multicolumn{2}{|c|}{ Unsatisfactory } & \\
\hline & No & $\%$ & No & $\%$ & No & $\%$ & No & $\%$ & \\
\hline General hygiene practices & 11 & 22 & 39 & 78 & 44 & 88 & 6 & 12 & $\begin{array}{c}\mathrm{X}^{2}=0.75 \\
0.03 *\end{array}$ \\
\hline Regular follow-up measures & 4 & 8 & 46 & 92 & 48 & 96 & 2 & 4 & $\begin{array}{c}\mathrm{X}^{2}=0.55 \\
0.04 *\end{array}$ \\
\hline Administration of medication & 9 & 18 & 41 & 82 & 45 & 90 & 5 & 10 & $\begin{array}{c}\mathrm{X}^{2}=0.60 \\
0.05^{*}\end{array}$ \\
\hline Proper following of nutrition & 10 & 20 & 40 & 80 & 46 & 92 & 4 & 8 & $\begin{array}{c}\mathrm{X}^{2}=0.65 \\
0.05^{*}\end{array}$ \\
\hline Psychological reassurance of the child. & 5 & 10 & 45 & 90 & 47 & 94 & 3 & 6 & $\begin{array}{c}\mathrm{X}^{2}=0.45 \\
0.04 *\end{array}$ \\
\hline
\end{tabular}

$*=$ Significant

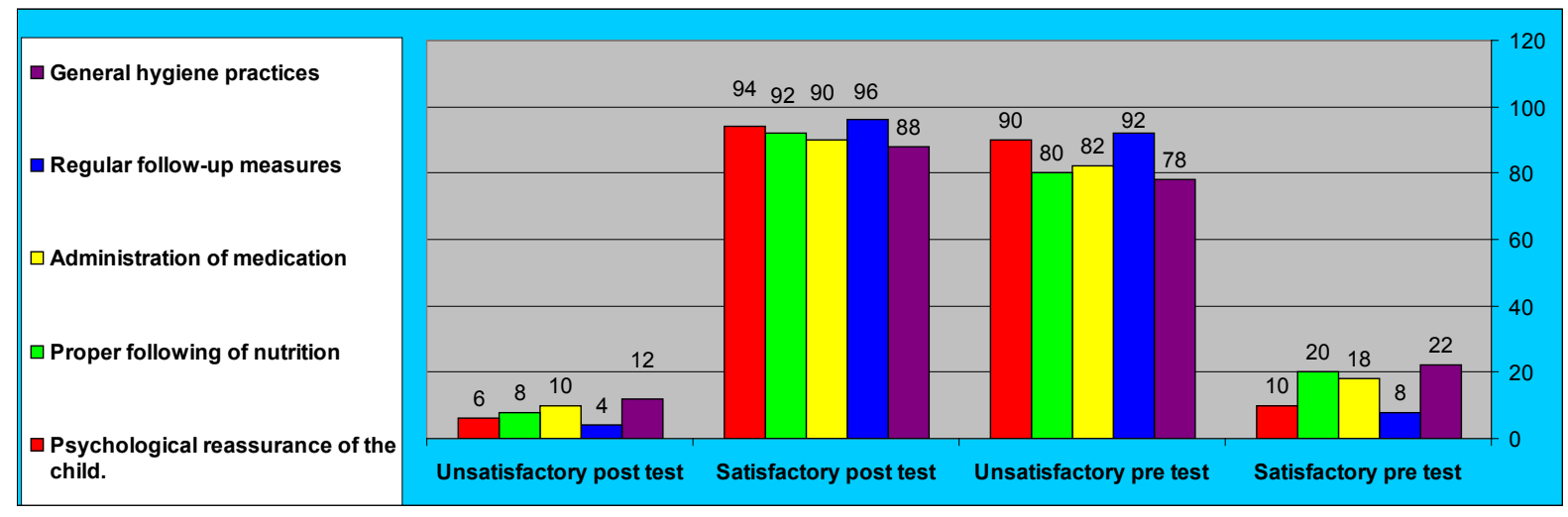

Figure 3. Distribution of mothers of pre-school children according to their reported health care practices

Table 5. The relation between the studied sample reported health care practices about nephrotic syndrome and their characteristics $\mathbf{n}_{=} \mathbf{5 0}$

\begin{tabular}{|c|c|c|c|c|c|c|}
\hline \multirow{3}{*}{ Items } & \multicolumn{4}{|c|}{ Knowledge } & \multirow{3}{*}{$\mathrm{X}^{2}$} & \multirow{2}{*}{$P$. value } \\
\hline & \multicolumn{2}{|c|}{ Satisfactory } & \multicolumn{2}{|c|}{ Unsatisfactory } & & \\
\hline & No & $\%$ & No & $\%$ & & \multirow{5}{*}{$0.01 *$} \\
\hline Age in years: & \multirow[b]{2}{*}{4} & \multirow[b]{2}{*}{8} & \multirow[b]{2}{*}{11} & \multirow[b]{2}{*}{22} & \multirow{4}{*}{0.52} & \\
\hline Under 20: 29 years & & & & & & \\
\hline From $30: 39$ Years & 10 & 20 & 9 & 18 & & \\
\hline 40 and more & 8 & 16 & 8 & 16 & & \\
\hline Formal education & \multirow[b]{2}{*}{4} & \multirow[b]{2}{*}{8} & \multirow[b]{2}{*}{10} & \multirow[b]{2}{*}{20} & \multirow{5}{*}{0.60} & \multirow{5}{*}{$0.01 *$} \\
\hline Cannot read and write & & & & & & \\
\hline Primary School & 3 & 6 & 8 & 16 & & \\
\hline Secondary School & 11 & 22 & 4 & 8 & & \\
\hline Higher Education & 3 & 6 & 7 & 14 & & \\
\hline Residence: & & & & & \multirow{3}{*}{0.70} & \multirow{3}{*}{$0.02 *$} \\
\hline Rural & 7 & 14 & 14 & 50 & & \\
\hline Urban & 6 & 12 & 12 & 24 & & \\
\hline Monthly income & & & & & \multirow{3}{*}{0.55} & \multirow{3}{*}{$0.03 *$} \\
\hline Adequate & 5 & 10 & 5 & 10 & & \\
\hline In-adequate & 10 & 20 & 30 & 60 & & \\
\hline
\end{tabular}




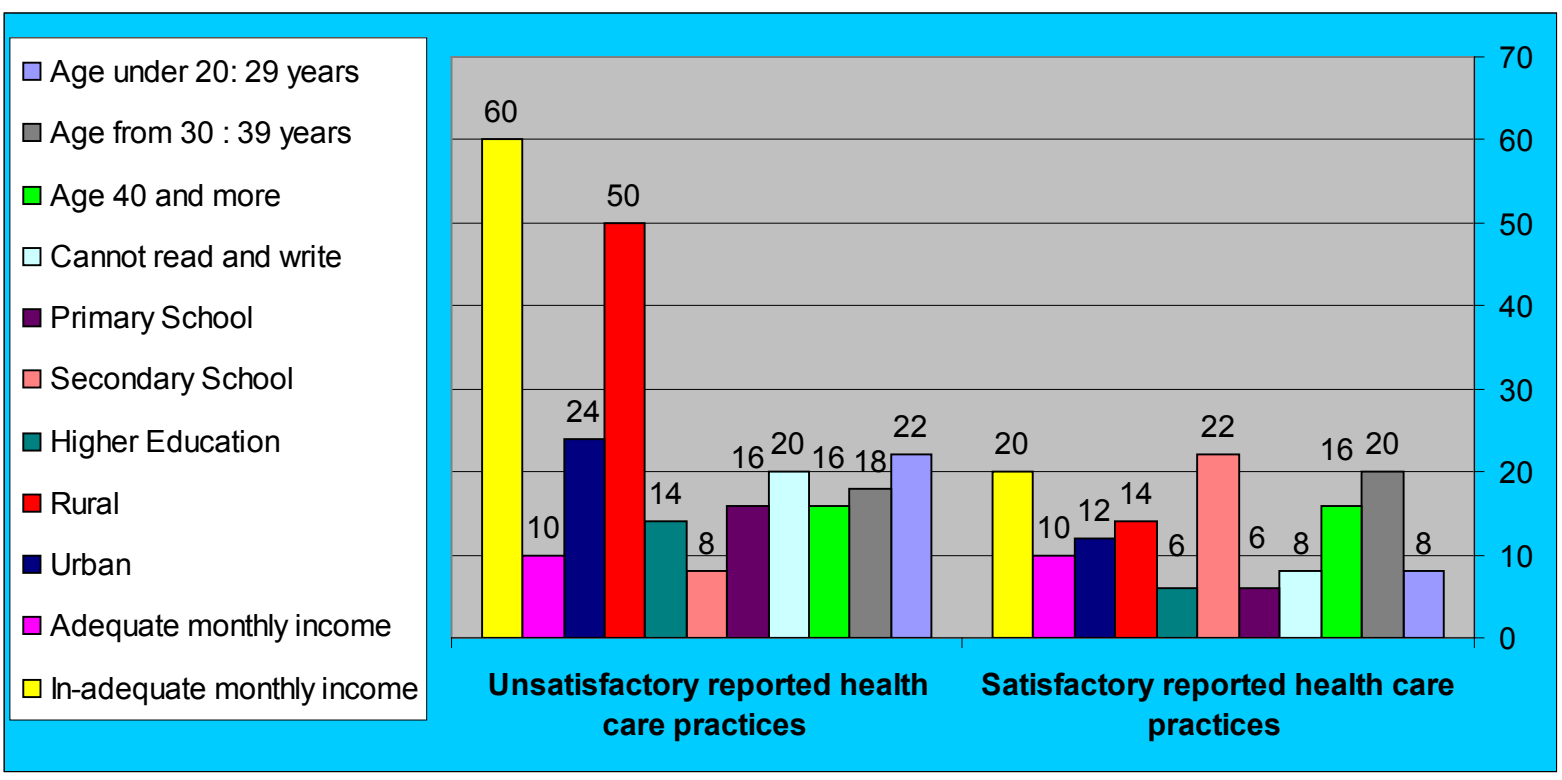

Figure 4. The relation between the studied sample reported health care practices about nephrotic syndrome and their characteristics

Table $5 \&$ Figure 4 this table revealed that, the relation between the studied samples reported health care practices about nephrotic syndrome in pre-school children and their characteristics. It indicates an increase in satisfactory reported health care practices of mothers age from 30:39 years were $20 \%, 22 \%$ of mothers have secondary school education, $14 \%$ of mothers in rural and $20 \%$ of mothers have in-adequate income. However, this increase reached statistically significant difference between the mothers age, formal education, residence and monthly income and their reported health care practices (P. 0.01, 0.01, 0.02and 0.03); respectively.

Table 6. The correlation between the total scores of mothers knowledge and reported health care practices in pre-test and posttest about nephrotic syndrome in the program $n=50$

\begin{tabular}{|c|c|c|}
\hline \multirow{2}{*}{ Pre-test } & \multicolumn{2}{|c|}{ Post-test } \\
\cline { 2 - 3 } & Correlation Coefficient (r) & P. value \\
\hline Knowledge & 0.89 & $0.002 *$ \\
\hline Reported health care practices & 0.95 & $0.001 *$ \\
\hline
\end{tabular}

*=Significant

Table 6 this table shows the correlation between the total scores of mothers knowledge and reported health care practices in pre-test and post-test about nephrotic syndrome. It is evident that the highest strong positive statistical significant correlation was found between the total scores of knowledge in pre-test and post-test program of mothers of pre-school children about nephrotic syndrome $(\mathrm{r}=0.88)$ and the highest strong positive statistical significant correlation was found between the total scores of reported health care practices in pre-test and post-test program of mothers of pre-school children about nephrotic syndrome $(\mathrm{r}=0.95)$.

\section{Discussion}

Regarding to personal data of mothers most of them were have secondary school and higher education level who have higher satisfactory knowledge, is in congruence with Suzan, et al., [18] who stated that personal data of the studied mothers, more than one quarter of them were illiterate so that as expected mothers educational level effect their level of knowledge which reflect on their care for their children with nephrotic syndrome, this result is similar to Abd el-aziz, [19] who studied mothers' care for children having nephrotic syndrome and indicated that mother with higher education were more responsive to information about herself and her child health care.

Regarding to mothers of pre- school children with nephrotic syndrome age, the highest percentage for their age is from 30:39 years old with mean age $36.3 \pm 9.2$. However, this age of mothers 30:39 years old who have satisfactory knowledge than younger or older age these results were in an agreement with Suzan, et al., [18] who reported that, the highest percentage for their age is between 30- 39 years old with mean age 33.70 \pm 6.37 . However, it is observed that mothers aged from 30-39 years old had more knowledge than younger or older age and that this may be due to their age they are able more to learn and gain information than other age group in the same context with Zyarah and Mua'ala, [20] who assessed 80 mothers' practices toward children with steroid sensitive nephrotic syndrome at pediatrics hospitals in Baghdad city college of nursing, they found that more than quarter of the mothers in the age group (30-34 years old).

The present study illustrated most of mothers have satisfactory knowledge about meaning, causes, signs and symptoms, investigations, specific diet, and oral medication for nephrotic syndrome in post-test was the same context with Suzan, et al., [18] who stated that, more than one quarter of the studied mothers had satisfactory level of knowledge about treatment of nephrotic syndrome. In relation to mothers' total knowledge and health care related practice level.

The current study showed that, there was reached to statistical significant correlation between mothers' knowledge regarding nephrotic syndrome and their level of education, place of residence and family income as 
mothers' knowledge was increased with age from 30:39 years old, highly educated mothers and mothers who live in areas rural than urban areas and by in-adequate family income. This result was not agreement supported by Mishra, et al., [21] who studied the behavioral abnormalities in children with nephrotic syndrome. They concluded that mothers had unsatisfactory level of knowledge due to their demographic characteristics as age, education, place of residence and family income.

The present study show the highest strong positive statistical significant correlation was found between the total scores of knowledge and reported health care practices in pre-test and post-test program of mothers of pre-school children about nephrotic syndrome, Sarika, [22] who stated that, parents have strong positive statistical significant correlation between knowledge and practices in pre-test program of parents regarding home management of children with nephrotic syndrome, Suzan, et al., [18] who reported that, There was highly statistical significant positive correlation between mothers' knowledge about their children with nephrotic syndrome and their reported health care related practice level.

Based on the study's results, the majority of mothers of pre-school children with nephrotic syndrome need health education programs for raising their level of knowledge and health related awareness this result is in congruent with Costa, et al., [15] who perform a qualitative study on how mothers perceive their children with the nephrotic syndrome. The authors suggested that formation of groups with mothers of children with nephrotic syndrome in the days of consultations to clarify more and more about the aspects of the disease and the importance of actions in their child's daily life; would be important to strengthen mothers' knowledge, at the time of the meetings in hospitalizations.

\section{Limitations of the Study}

Sometimes difficult to found place in hospital to collect mothers of pre-school children to attend the program.

\section{Conclusion}

Based on result of the present study the mothers of pre-school children knowledge and health care practices about nephrotic syndrome in pediatric word at Minia University Hospital for Obstetrics and Pediatrics were lacking the necessary basic knowledge and health care practices about nephrotic syndrome so, educational program was based on mothers needs of knowledge, health care practices this came from pre-test results. Mother's age, education, place of residence and family income reached statistical significance difference with mothers' knowledge and reported health care practices. By the implementation of the program there was remarkable improvement of mothers knowledge and reported health care practices, it was clear in post-test results. By the end of the program there was successful in correcting the deficiency in mothers knowledge and health care practices.

\section{Recommendations}

On the light of the findings of the current study, the following were recommended: Nurses should provide educational classes for the mothers about nephrotic syndrome to elevate their level of health awareness about disease and its care. As well provide the mothers with Arabic leaflet as useful source of information at home in addition to mass media should provide educational mass media programs for such diseases. The developed program should be applied in the same study setting and adopted in other similar settings with required modifications, provision of continuing education programs. On regular basis is suggested in order to refresh and update mothers knowledge about nephrotic syndrome in pre-school children.

\section{References}

[1] Ghai OP, Piyush Gupta, Paul VK., (2013): Ghai Essential Pediatrics. 8th ed. New Delhi: CBS Publishers and distributors; 2013:552-560

[2] Saraswathi K.N., Kavya R., Lissa J. and Anitha S.L., (2013): A Study to assess the knowledge on Nephrotic Syndrome among mothers of children admitted with Nephrotic Syndrome in Indira Gandhi Institute of Child Health, Bangalore. Asian Journal of Nursing Education and Research, 3 (1): 1.

[3] Jerome C., (2011): Pediatric nephrotic syndrome treatment and management. Northwestern University, Medscape Reference.

[4] Zolotas E. and Krishnan R.G., (2011): Nephrotic syndrome. Pediatrics and Child Health.

[5] Lane J.C. and Langman B.C., (2015): Pediatric Nephrotic Syndrome. Available at http://www.medscape.com.

[6] Roberto Gordillo and Adrian Spitzer., (2009): The Nephrotic Syndrome. Pediatrics in Review. 2009;30(2):94-104

[7] Levin M, (2009): New Treatment in Nephrotic Syndrome. Research, 14: 2-3. P. 1-8.

[8] Zhang H., Wang Z., Dong L., Guo Y., Wu j. and Zhai S., (2009): New insight into the pathogenesis of minimal change nephrotic syndrome: Role of the persistence of respiratory tract virus in immune disorders. Autoimmunity reviews, 15 (7): 632-7.

[9] Hussien H.A. and Sadek B.R.A., (2011): Adjustment oral fluids intake on decreasing edema among children with nephrotic syndrome. World Journal of Medical Sciences, 8 (4): 408-17.

[10] Alharthi A.A., (2011): Patterns of childhood steroid-sensitive and steroid-resistant nephrotic syndrome in Saudi children Clinicopathological study of 87 Cases. Clinical Pediatric.

[11] Hockenberry M.J. and Wilson D., (2014): Wong's nursing care of infants and children $9^{\text {th }}$ ed. Elsevier Health Sciences. 11(5): 4-8.

[12] Lombel R.M., Gipsone D.S. and Hodson E.M., (2013): Treatment of steroid-sensitive nephrotic syndrome: New guidelines from KDIGO. Pediatric Nephrology, 28 (3): 415-26.

[13] Andolino T.P. and Adam J.R., (2015): Nephrotic syndrome. American Academy of Pediatrics, Journal of Pediatric in Review, 36 (3): 117-26, 2015.

[14] Gipson D.S., Messer K.L., Tran C.L., Herre Shoff E.G., Samuel J.P., MassenGill S.F., Song P. and Selewski D.T., (2013): Inpatient health care utilization in the United States among children, adolescents, and young adults with nephrotic syndrome. American Journal of Kidney Diseases, 61 (6): 910-7

[15] Costa W.K., Moreira R.T., Lucio I.M., and Cavalcante L.P., (2015): How mothers perceive their children with the nephrotic syndrome. Journal of Nursing UFPE on line, 9 (2): 624-32.

[16] World Health Organization (2011): International statistical classification of diseases and related health problems (Vol. 1). World Health Organization.

[17] Amro A.H., Hagras A.M, El-Attar M.M. and Helmy S.M., (2012): Nephrotic syndrome in Egyptian children: A single Centre experience. CU Theses. 
[18] Suzan I, Khider, M.S., Afkar R., Mohamed, D.N, Naglaa F, Mahmoud, D.N., and Rasha Essame, M.D., (2017): Nephrotic Syndrome Knowledge and Health Care Related Practices among School Age Children and their Mothers Med. J. Cairo Univ., Vol. 85, No. 2, March: 515-522. www.Medicaljournal ofcairoun versity.net

[19] Abd el-aziz H, (2012): Mothers' care for children having nephritic syndrome, Unpublished master thesis, Ain Shams University, Faculty of Nursing, Pediatric Nursing Department.

[20] Zyarah F., and Mua'ala F., (2013): Assessment of mothers' practices toward children with steroid-sensitive nephrotic syndrome at pediatrics hospitals in Baghdad city college of nursing, university of Baghdad. Iraqi National Journal of Nursing Specialties, 24 (2): 13-25.

[21] Mishra O.P., Basu B., Upadhyay S.K., prasad R. and Schaefer F., (2013): Behavioral abnormalities in children with nephrotic syndrome. Nephrology Dialysis Transplantation, 25: 2537-41.

[22] Sarika, (2017): Assessment of Knowledge and Practices of Parents Regarding Home Management of Children with Nephrotic Syndrome at Selected Hospitals of Haryan, India. Int. J. Curr. Microbiol. App. Sci. 6(10): 1496-1503.

[23] www.medicaljournalofcairouniversity.net 